\title{
Cigarette smoking and smoking cessation among older adults: United States, 1965-94
}

\author{
Corinne G Husten, Dana M Shelton, Jeffrey H Chrismon, Yun-Chen W Lin, \\ Paul Mowery, Felicia A Powell
}

\begin{abstract}
Objective-To characterise patterns of cigarette smoking and smoking cessation among older adults in the United States.

Design-Data from the National Health Interview Surveys (NHIS) 1965-94 were analysed. The NHIS is a cross-sectional survey using a representative national sample.

Setting-In most cases interviews were conducted in the home; telephone interviews were conducted when respondents could not be interviewed in person.

Participants-Participants were from a representative sample of the American civilian, non-institutionalised population aged 18 and older. Sample sizes for the years analysed ranged from $n=19738$ to $n$ $=138988$ overall, and $n=3806$ to $n=$ 12491 for those aged 65 years and older.

Main outcome measures-Using the NHIS data from 1965-94, trends in current smoking and the prevalence of smoking cessation by demographic characteristics among older adults (65 years and older) were assessed and compared with trends among younger adults. A logistic regression analysis was conducted to determine the demographic characteristics of former smokers compared with current smokers among those aged 65 and older.
\end{abstract}

Results-The prevalence of current smoking among 65 year olds and older declined from 1965 to $1994(17.9 \%$ to $12.0 \%)$. Although smoking prevalence was lower among older adults than younger adults (aged 18-64), the rate of decline in smoking was slower among older adults. Among older adults, the prevalence of cessation rose with increasing educational attainment, and was consistently higher for men than for women and for whites compared with blacks. After adjustment for demographic factors among older adults who had ever smoked, increasing age and educational attainment were strongly related to the likelihood of being a former smoker. Although there were no racial differences among women, older white $(O R=2.6)$ and Hispanic $(O R=3.67)$ men were significantly more likely to be former smokers than older black men.
Also, the gender difference in smoking cessation was noted only for whites. Conclusions-Given the projected in- $v$ crease in the elderly population, the medi- $]$ cal and economic consequences of $\overrightarrow{C S}$ smoking will become a greater burden in $\mathbb{D}$ the next decades. Therefore, focusing $\mathbb{D}$ attention on cessation among the elderly is $\overline{0}$ an immediate and urgent priority for $\stackrel{\mathbb{Q}}{-}$ public health professionals and clinicians. $\overrightarrow{0}$

(Tobacco Control 1997;6:175-180)

Keywords: elderly; cigarette smoking; smoking cessation

\section{Introduction}

By $2020,17 \%$ of the United States population will be aged 65 and older. ${ }^{1}$ Many studies have $\frac{}{3}$ found that those 65 years of age and older who are current smokers have a higher overall risk of death than their counterparts who have never smoked. ${ }^{2-6}$ Specifically, older adults who 음 smoke have increased risk of cardiovascular disease, stroke, cancer, and respiratory disease..$^{2-5,7-12}$ In 1990 , smoking caused an estimated 287000 deaths in the United States from these diseases among those 65 years of age and older. ${ }^{13}$

In the United States population, the mortal- $\delta$ ity effects of smoking occur primarily among older Americans. For example, in $1990,70 \%$ of 윽 the estimated 419000 smoking-attributable deaths occurred among people aged 65 and older; $86 \%$ of smoking-attributable deaths $N$ from chronic obstructive pulmonary disease, $64 \%$ of smoking-attributable deaths from lung $N$ cancer, and $65 \%$ of smoking-attributable $\omega$ deaths from ischaemic heart disease occurred among older adults. ${ }^{13}{ }^{14}$ Clearly, tobacco use is a geriatric health issue.

Cigarette smoking not only increases risk of death among older adults but also affects quality of life. The increased risk of disability from $\stackrel{\mathbb{D}}{\circ}$ malignant neoplasms, heart disease, cerebro- $\mathbb{Q}$ vascular disease, chronic obstructive pulmonary diseases, and other diseases caused by smoking adversely affects quality of life and 0 physical functioning. ${ }^{15} 16$ In addition, smoking affects drug action and metabolism. ${ }^{17}$

Quitting smoking has major and immediate benefits for smokers of all ages, and these benefits accrue to those who already have smoking-related diseases, as well as to those who do not. ${ }^{6}$ Smoking cessation at any age 
reduces the overall risk of death. ${ }^{6}{ }^{18}$ For example, if a person aged 60-64 years who smokes one pack of cigarettes or more per day quits smoking, they reduce their risk of dying in the next 15 years by $10 \% .^{6}$ Reduction in risk occurs relatively quickly for some diseases. For example, among older adults, the reduction in risk for developing cardiovascular disease occurs within one to five years after quitting. ${ }^{8}$ Quitting smoking also reduces the risk of recurrent myocardial infarction and death among those with cardiovascular disease. Hermanson et al. found that those 55 years of age or older who already had coronary artery disease improved their survival and risk of myocardial infarction by quitting smoking. Adults 65 years of age or older improved their survival comparable to their younger counterparts. ${ }^{18}$ Smoking cessation among older adults also decreases the risk of developing lung and other cancers. Among those aged 65 years or older, the estimated relative risks compared with continuing smokers were 0.73 with five years of abstinence, 0.54 with 10 years of abstinence, and 0.29 with 20 years of abstinence. ${ }^{6}$ Finally, studies have demonstrated that older former smokers have better physical functioning and quality of life measures than older current smokers. ${ }^{19} 20$

With the proportion of older Americans growing steadily, the health of this segment of the population is an increasing focus of public health efforts in the United States. The aim of the study was to contribute to these efforts by characterising the patterns of smoking and smoking cessation among American adults aged 65 and older.

\section{Methods}

Data from the National Health Interview Survey (NHIS) from 1965-94 were analysed in approximately five-year intervals (depending on data availability). The NHIS collects self-reported information on cigarette smoking from a representative sample of the American civilian, non-institutionalised population aged 18 and older. In most cases, the NHIS surveys were conducted in the home; telephone interviews were conducted when respondents could not be interviewed in person. Before 1974, the NHIS used proxy responses; because proxy information on smoking status is generally considered to be comparable to self-report, ${ }^{21-23}$ proxy responses were included in the analysis. The overall response rate for the NHIS for $1965-90$ was at least $85 \%{ }^{24}$; the response rates for the 1993 and 1994 surveys were $81 \%$ and $80 \%$, respectively. ${ }^{25} 26$

Participants ( $\mathrm{n}=19738-138988$ overall; $n$ = 3806-12 491 for those 65 years of age or older) were asked standard questions to determine their smoking status. Smokers were categorised as ever-smokers if they had smoked at least 100 cigarettes in their lifetime. To evaluate the prevalence of current smoking, ever-smokers were asked in the surveys for 1965-90 if they "smoke cigarettes now" and in the 1993 and 1994 surveys if they now smoked "every day or some days"; respondents who answered affirmatively were considered current smokers. The prevalence of cessation was defined as the proportion of ever-smokers who did not currently smoke.

For reporting and modelling the demographic factors associated with smoking cessation among older adults, data from the 1993 and 1994 surveys were aggregated to increase the sample size. All data were adjusted for nonresponse and weighted to provide national estimates. For the data for $1965,95 \%$ confidence intervals (CIs) were calculated using variance curves $^{27}$; for later years, CIs were calculated using standard errors generated by SUDAAN. ${ }^{28}$ CIs were used to determine statistical significance. This is a conservative method of determining statistical significance; estimates with slightly overlapping CIs may be significant at the $\mathrm{P}=0.05$ level. A logistic regression analysis was conducted to determine the demographic characteristics of former smokers compared with current smokers among those aged 65 and older. The model was built and diagnosed using strategies recommended by Hosmer and Lemeshow. ${ }^{29}$ The Hosmer-Lemeshow goodness-of-fit test showed that the model fits the data well.

\section{Results}

TRENDS OVER TIME

The prevalence of ever-smoking among men aged 65 or older increased from $56.6 \%( \pm 2.5$ percentage points) in 1965 to $72.2 \%( \pm 2.4$ percentage points) in 1985 and then remained stable $(71.6 \% \quad[ \pm 2.5$ percentage points $]$ in 1994) (data not shown). The prevalence of ever-smoking among women continued to increase from $14.1 \%( \pm 1.6$ percentage points $)$ in 1965 to $38.0 \%$ ( \pm 2.2 percentage points) in 1994 (data not shown).

Current smoking prevalence was lower among those aged 65 and older than among adults aged 18-64 from 1965 to 1994 . The prevalence of current smoking among 65 year olds and older decreased from 1965 to 1994 (from $17.9 \%$ to $12.0 \%$ ); however, most of the decline occurred between 1985 and 1990. For younger adults (aged 18-64 years), the decline was larger and occurred over the entire period from 1965 to 1990 (table 1). The average annual rate of decline in the prevalence of current smoking during this period was three times slower for older adults than younger adults $(0.20$ percentage points for people aged 65 and older compared with 0.63 percentage points for those aged 64 and younger). For older men, smoking prevalence dropped steadily over this time period from $28.5 \%$ to $13.2 \%$; among older women, smoking prevalence increased until 1985 and subsequently stabilised at around $11 \%$. In contrast, among younger adults of both sexes, smoking prevalence decreased until 1990 and then stabilised.

From 1965-94, current smoking prevalence among older adults declined for whites but not for blacks. In contrast, among 64 year olds and younger, smoking prevalence declined for both whites and blacks from 1965 to 1990 and remained constant from 1990 to 1994 . Sample sizes were too small to assess trends in other 
racial or ethnic groups. There was no decrease in current smoking prevalence among older people with 11 or fewer years of education, although prevalence declined among older people with 12 or more years of education (table 1). In contrast, among younger adults, prevalence declined for all levels of education except for those with 9-11 years of education.

In 1994, there were no gender differences in current smoking prevalence among older adults; however, among younger adults, smoking prevalence was lower among women. Older blacks $(18.7 \%)$ were more likely to smoke than were older whites (11.6\%); among younger adults, smoking prevalence for blacks and whites was similar. Older adults with 16 or more years of education were less likely to smoke than were older people with eight or fewer years of education; in general, however, educational differences in current smoking among older Americans were smaller than those among younger adults. Only in 1994 was there a significant difference in smoking prevalence between the lowest and highest educational categories. In contrast, among younger adults, there were significant differences across educational categories for all years.

The prevalence of cessation (also referred to as the "quit ratio") among those aged 65 and older increased steadily from $45.5 \%$ in 1965 to $76.9 \%$ in 1994; the prevalence of cessation among younger adults increased from 1965 to 1990 and then stabilised (table 2). Although the prevalence of cessation was consistently higher among older men than older women from 1965 to 1994 , it increased more quickly among older women than older men (an aver- age of 1.33 percentage points a year for olderoำ women compared with 1.09 percentage points a year for older men). The same generalo pattern was seen among younger adults. Although the rate of increase was somewhat:smaller among younger adults than older $\overrightarrow{\overline{\vec{A}}}$ adults, similar racial patterns were observed for the two age groups. For older adults, the preva-흐 lence of cessation increased among alloक educational categories, with the smallest $\stackrel{\Phi}{\Phi}$ increase among older adults with 11 or fewero years of education; for younger adults, those with 9-12 years of education had a slower rate of increase (table 2).

In 1994, the prevalence of cessation was much higher for older men $(81.5 \%)$ than for older women $(70.7 \%)$, a more dramatic gender $\omega$ difference than that observed among younger adults. The prevalence of cessation was also $\mathrm{G}$ higher among older whites $(78.0 \%)$ than older 을 blacks $(60.9 \%)$, a pattern comparable to that $\vec{c}$ among younger adults. Among older adults, $\mathbb{D}$ the prevalence of cessation increased directly with increasing educational attainment, from 3 $69.0 \%$ among older people with eight years of education or less to $83.3 \%$ among older adults $\vec{\varphi}$ with 16 or more years of education. In $\theta$ contrast, younger adults with $0-8$ years of education had a higher prevalence of cessation than those with 9-11 years of education; however, prevalence of cessation for younger adults increased as educational attainment increased from $9-11$ to 16 or more years of education.

DEMOGRAPHIC DIFFERENCES AMONG FORMER SMOKERS VS CURRENT SMOKERS, 1993-94 Among older adults, based on a model that included age, sex, race, and education, the like- $\frac{0}{0}$ lihood of being a former smoker increased with

Table 1 Prevalence of current smoking among people by age and other selected characteristics: United States, 1965-94

\begin{tabular}{|c|c|c|c|c|c|c|c|c|c|c|c|c|c|c|}
\hline Characteristic & $\begin{array}{c}1965 \\
(\%)\end{array}$ & $(95 \% C I)$ & $\begin{array}{c}1970 \\
(\%)\end{array}$ & $(95 \% C I)$ & $\begin{array}{c}1974 \\
(\%)\end{array}$ & $(95 \% C I)$ & $\begin{array}{l}1979 \\
(\%)\end{array}$ & $(95 \% C I)$ & $\begin{array}{l}1985 \\
(\%)\end{array}$ & $(95 \% C I)$ & $\begin{array}{l}1990 \\
(\%)\end{array}$ & $(95 \% C I)$ & $\begin{array}{l}1994 \\
(\%)\end{array}$ & $(95 \% C I)$ \\
\hline \multicolumn{15}{|l|}{ Age 65+ } \\
\hline $\begin{array}{l}\text { Overall } \\
\text { Sex }\end{array}$ & 17.9 & $(16.7-19.1)$ & 16.1 & $(15.2-17.1)$ & 17.3 & $(47.5-49.9)$ & 16.4 & $(15.3-17.5)$ & 16.0 & $(14.9-17.1)$ & 12.8 & $(11.9-13.7)$ & 12.0 & $(10.9-13.1)$ \\
\hline Men & 28.5 & $(26.5-30.5)$ & 23.1 & $(21.7-24.5)$ & 24.8 & $(22.6-27.0)$ & 20.9 & $(18.9-22.9)$ & 19.6 & $(17.5-21.7)$ & 14.6 & $(13.0-16.2)$ & 13.2 & $(11.3-15.1)$ \\
\hline Women & 9.6 & $(8.6-10.6)$ & 11.0 & $(9.9-12.1)$ & 12.0 & $(10.8-13.2)$ & 13.2 & $(11.9-14.5)$ & 13.5 & $(12.2-14.8)$ & 11.5 & $(10.6-12.4)$ & 11.1 & $(9.8-12.4)$ \\
\hline \multicolumn{15}{|c|}{$12.0(10.0-13.2) \quad 15.2(11.9-14.5) \quad 13.3(12.2-14.0) 11.3 \quad(10.0-12.4) \quad 11.1$} \\
\hline White & 17.7 & $(16.6-18.8)$ & 16.0 & $(15.1-16.9)$ & 17.2 & $(16.0-18.4)$ & 16.2 & $(15.0-17.4)$ & 15.6 & $(14.5-16.7)$ & 12.5 & $(11.6-13.4)$ & 11.6 & $(10.5-12.7)$ \\
\hline Black & 20.1 & $(15.4$ & 18.7 & $(16.1-21.3)$ & 17.8 & $(13.7-21.9)$ & 16.6 & $(12.1-21.1)$ & 19.7 & $(15.9-23.5)$ & 15.4 & $(12.3-18.5)$ & 18.7 & $(14.2-23.2)$ \\
\hline \multicolumn{15}{|c|}{ 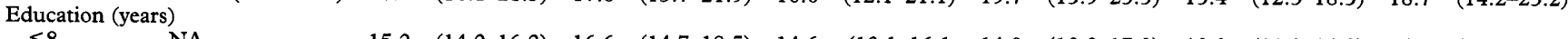 } \\
\hline$\leqslant 8$ & NA & & 15.2 & $(14.2-16.2)$ & 16.6 & $(14.7-18.5)$ & 14.6 & $(13.1-16.1$ & 14.9 & $(12.8-17.0)$ & 13.0 & $(11.2-14.8)$ & 14.8 & $(12.2-17.4)$ \\
\hline $9-11$ & NA & & 16.5 & $(14.5-18.5)$ & 19.3 & $(15.9-22.7)$ & 19.4 & $(16.4-22.4)$ & 18.2 & $(15.2-21.0)$ & 14.4 & $(12.1-16.7)$ & 13.9 & $(11.1-16.7)$ \\
\hline 12 & NA & & 17.8 & $(15.6-20.0)$ & 16.1 & $(13.3-18.9)$ & 17.4 & $(14.9-19.9)$ & 17.4 & $(15.5-19.3)$ & 13.5 & $(12.0-15.0)$ & 10.7 & $(9.0-12.4)$ \\
\hline $13-15$ & NA & & 18.9 & $(15.5-22.3)$ & 17.9 & $(12.6-23.2)$ & 19.0 & $(14.9-23.1)$ & 15.9 & $(12.9-18.9)$ & 11.3 & $(9.1-13.5)$ & 11.9 & $(8.9-14.9)$ \\
\hline$\geqslant 16$ & NA & & 17.3 & $(14.1-20.5)$ & 18.3 & $(12.7-23.9)$ & 14.0 & $(9.6-18.4)$ & 12.4 & $(9.4-15.4)$ & 9.3 & $(7.1-11.5)$ & 8.9 & $(6.0-11.8)$ \\
\hline \multicolumn{15}{|l|}{ Age 18-64 } \\
\hline $\begin{array}{l}\text { Overall } \\
\text { Sex }\end{array}$ & 46.6 & $(46.0-47.2)$ & 41.0 & $(40.4-41.6)$ & 40.7 & $(39.9-41.5)$ & 36.6 & $(35.7-37.5)$ & 32.7 & $(31.9-33.5)$ & 28.0 & $(27.4-28.6)$ & 28.2 & $(27.4-29.0)$ \\
\hline Men & 55.6 & $(54.8-56.4)$ & 47.3 & $(46.5-48.1)$ & 46.0 & $(44.9-47.1)$ & 40.1 & $(38.9-42.5)$ & 34.7 & \multicolumn{5}{|c|}{ Sex } \\
\hline Women & 38.3 & $(37.5-39.1)$ & 35.4 & $(34.5-36.3)$ & 36.1 & $(35.2-37.0)$ & 33.3 & $(32.2-34.4)$ & $\begin{array}{l}34.7 \\
30.9\end{array}$ & $(30.0-31.8)$ & $\begin{array}{l}30.8 \\
25.4\end{array}$ & 31.7) & $\begin{array}{l}30.7 \\
25.8\end{array}$ & $\begin{array}{l}(29.5-31.9) \\
(24.7-26.9)\end{array}$ \\
\hline \multicolumn{15}{|c|}{ Race/ethnicity $\dagger$} \\
\hline White & 46.4 & 47.0) & 40.8 & $(40.2-41.4)$ & 39.9 & $(39.0-40.8)$ & 36.8 & $(35.9-37.7)$ & 32.9 & $(32.0-33.8)$ & 28.8 & $(28.1-29.5)$ & 29.6 & $-30.6)$ \\
\hline Black & 49.1 & $(47.4-50.8)$ & 44.4 & $(42.8-46.0)$ & 47.8 & $(45.3-50.3)$ & 40.4 & $(38.0-42.4)$ & 37.1 & $(35.1-39.1)$ & 27.7 & $(26.1-29.3)$ & 28.3 & $(25.8-30.8)$ \\
\hline \multicolumn{15}{|c|}{ 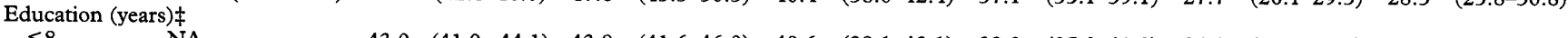 } \\
\hline$\leqslant 8$ & NA & & 43.0 & $(41.9-44.1)$ & 43.8 & $(41.6-46.0)$ & 40.6 & $43.1)$ & 38.2 & $-41.2)$ & 34.1 & 6.8) & 31.9 & 5.6) \\
\hline $9-11$ & NA & & 49.4 & $(48.2-50.6)$ & 50.6 & $(48.6-52.6)$ & 49.2 & $(47.2-51.2)$ & 49.2 & $(47.0-51.4)$ & 45.7 & $(43.6-47.8)$ & 48.4 & $(45.3-51.5)$ \\
\hline 12 & NA & & 41.3 & $(40.4-42.2)$ & 41.2 & $(40.1-42.3)$ & 37.7 & $(36.3-39.1)$ & 36.1 & $(34.8-37.4)$ & 33.5 & $(32.4-34.6)$ & 34.0 & $(32.5-35.5)$ \\
\hline $13-15$ & NA & & 41.0 & $(39.5-42.5)$ & 40.2 & $(38.0-42.4)$ & 37.1 & $(35.5-38.7)$ & 32.5 & $(30.9-34.1)$ & 26.5 & $(25.3-27.7)$ & 27.7 & $(25.9-29.5)$ \\
\hline$\geqslant 16$ & NA & & 29.9 & $(28.4-31.4)$ & 29.8 & $(27.7-33.0)$ & 24.7 & $(23.0-26.4)$ & 19.7 & $(18.4-21.0)$ & 14.5 & $(13.6-15.4)$ & 12.7 & $(11.5-13.9)$ \\
\hline
\end{tabular}

Source: National Health Interview Survey (NHIS), 1965, 1970, 1974, 1979, 1985, 1990, and 1994.

^Persons who reported smoking at least 100 cigarettes in their lifetime and who smoked at the time of survey. Since 1992, estimates of current smoking explicitly include someday smokers.

†Ethnicity not determined by NHIS in 1965, 1970, or 1974 .

¥Aged 25 and older only.

$\mathrm{CI}=$ confidence intervals; $\mathrm{NA}=$ not available. 
increasing age and educational attainment (table 3). People aged 70-74 (OR = 1.37), aged $75-79(\mathrm{OR}=1.51)$, and aged 80 and older $(\mathrm{OR}=2.19)$ were significantly more likely to be former smokers than those aged 65-69. In addition, older people with some college education $(\mathrm{OR}=1.44)$ and those who completed college $(\mathrm{OR}=1.55)$ were significantly more likely to have quit smoking than were older adults with 9-11 years of education. Interaction was found only by gender and race. There were no racial differences in cessation among older women. However, among older men, whites $(\mathrm{OR}=2.6)$ and Hispanics $(\mathrm{OR}=3.67$ ) were more likely to be former smokers than were blacks. After controlling for age, race, and education, older white men (OR $=1.95)$ were more likely than older white women to be former smokers (data not shown).

\section{Discussion}

The gender differences in the pattern of ever-smoking are consistent with historical trends in smoking prevalence. Smoking among men was highest in the 1920-30 birth cohorts, ${ }^{30}$ which would be reflected in peak rates of ever-smoking among older men from 1985-95; for women, smoking was greatest among the 1930 and 1940 birth cohorts, ${ }^{31}$ and one would expect ever-smoking among older women to increase until about the year 2005. A study by the National Institute on Aging found that the eldest older adults were more likely to be never-smokers, consistent with these historical patterns of smoking. ${ }^{31}$

Although current smoking prevalence among older adults declined from $17.9 \%$ to
$12.0 \%$ from 1965 to 1994 , the total number of smokers aged 65 years and older actually increased $20 \%$ (from 3.078 million to 3.687 million) because of population growth in this age group. Despite the lower prevalence of smoking among older adults, the sheer numbers of the aging "baby boomer" generation will contribute to a continued growth in the number of older smokers into the next century. ${ }^{32}$ The medical and economic burden of smoking will also grow. United States social security currently pays $\$ 4.6$ billion in disability benefits a year to people who are disabled by tobacco-related diseases, and it is estimated that Medicare will pay $\$ 800$ billion to treat tobacco-related diseases over the next 20 years. ${ }^{33}$ The lower prevalence of cessation among older women than among older men has been noted by others, ${ }^{31}$ and is thought to reflect gender differences in the historical patterns of smoking. ${ }^{34}$ Men began to quit smoking in large number in the 1950s, whereas women did not begin quitting in substantial numbers until the mid-1960s. ${ }^{35}$ Because the prevalence of cessation measure is a cumulative measure over time, and men began quitting earlier in the century than did women, the prevalence of cessation is higher for men. It has been reported that age-adjusted cessation and relapse rates among older adults do not vary by sex, ${ }^{36}$ and that women and men are equally likely to attempt to quit and equally likely to succeed. ${ }^{37}$ If the difference is due to these historical patterns of smoking and quitting, one would expect any sex difference in the prevalence of cessation to be greatest among the elderly; the results of this study are consistent with this expected pattern. The

Table 2 Prevalence of cessation * among people by age and other selected characteristics: United States, 1970-94

\begin{tabular}{|c|c|c|c|c|c|c|c|c|c|c|c|c|c|c|}
\hline Characteristic & $\begin{array}{c}1965 \\
(\%)\end{array}$ & $(95 \% C I)$ & $\begin{array}{c}1970 \\
(\%)\end{array}$ & $(95 \% C I)$ & $\begin{array}{c}1974 \\
(\%)\end{array}$ & $(95 \% C I)$ & $\begin{array}{c}1979 \\
(\%)\end{array}$ & $(95 \% C I)$ & $\begin{array}{c}1985 \\
(\%)\end{array}$ & $(95 \% C I)$ & $\begin{array}{c}1990 \\
(\%)\end{array}$ & $(95 \% C I)$ & $\begin{array}{c}1994 \\
(\%)\end{array}$ & $(95 \% C I)$ \\
\hline \multicolumn{15}{|l|}{ Age 65+ } \\
\hline Overall & 45.5 & $(43.1-47.9)$ & 56.9 & $(55.0-58.8)$ & 57.5 & $(55.1-59.9)$ & 62.7 & $(60.3-65.1)$ & 68.0 & $(66.1-69.9)$ & 74.1 & $(72.5-75.7)$ & 76.9 & $(75.0-78.8)$ \\
\hline \multicolumn{15}{|l|}{ Sex } \\
\hline Men & 49.7 & $(47.0-52.4)$ & 63.2 & $(61.1-65.3)$ & 62.7 & $(59.8-65.6)$ & 69.2 & $(66.3-72.1)$ & 72.8 & $(70.1-75.5)$ & 79.1 & $(76.9-81.3)$ & 81.5 & $(79.0-85.0)$ \\
\hline Women & 32.2 & $(27.5-36.9)$ & 41.0 & $(37.9-44.1)$ & 46.9 & $(42.8-51.0)$ & 51.3 & $(47.1-55.5)$ & 61.1 & $(58.3-63.9)$ & 67.0 & $(64.6-69.4)$ & 70.7 & $(67.5-73.9)$ \\
\hline \multicolumn{15}{|c|}{ Race/ethnicity } \\
\hline White & 46.2 & $(43.7-48.7)$ & 57.7 & $(55.8-59.6)$ & 58.1 & $(55.7-60.5)$ & 63.8 & $(61.3-66.3)$ & 69.3 & $(67.4-71.2)$ & 75.3 & $(73.6-77.0)$ & 78.0 & $(76.0-80.0)$ \\
\hline Black & 37.5 & $(27.2-47.8)$ & 44.1 & $(37.6-50.6)$ & 50.9 & $(42.3-59.5)$ & 55.4 & $(46.8-64.0)$ & 55.9 & $(48.6-63.2)$ & 63.0 & $(56.4-69.6)$ & 60.9 & $(53.1-68.7)$ \\
\hline \multicolumn{15}{|c|}{ Education (years) } \\
\hline$\leqslant 8$ & NA & & 57.4 & $(55.0-59.8)$ & 56.1 & $(52.4-59.8)$ & 63.7 & $(60.4-67.0)$ & 67.6 & $(63.4-71.8)$ & 71.2 & $(67.6-74.8)$ & 69.0 & $(64.2-73.8)$ \\
\hline $9-11$ & NA & & 58.4 & $(53.8-63.0)$ & 59.5 & $(53.2-65.8)$ & 58.7 & $(53.4-64.0)$ & 64.0 & $(59.2-68.8)$ & 71.6 & $(67.5-75.7)$ & 73.9 & $(68.9-78.9)$ \\
\hline 12 & NA & & 55.9 & $(51.8-60.0)$ & 60.5 & $(55.1-65.6)$ & 61.8 & $(56.8-66.8)$ & 66.0 & $(62.4-69.6)$ & 72.6 & $(69.7-75.5)$ & 79.0 & $(75.8-82.2)$ \\
\hline $13-15$ & NA & & 47.5 & $(41.1-53.9)$ & 58.3 & $(48.2-68.4)$ & 61.6 & $(54.2-69.0)$ & 70.8 & $(65.3-76.3)$ & 79.1 & $(75.2-83.0)$ & 79.7 & $(74.7-84.7)$ \\
\hline$\geqslant 16$ & NA & & 59.9 & $(53.4-66.4)$ & 58.0 & $(47.4-68.6)$ & 72.5 & $(63.9-81.1)$ & 77.5 & $(72.6-82.4)$ & 82.0 & $(78.0-86.0)$ & 83.3 & $(78.3-88.3)$ \\
\hline \multicolumn{15}{|l|}{ Age 18-64 } \\
\hline Overall & 22.3 & $(21.6-23.0)$ & 30.5 & $(29.7-31.3)$ & 31.7 & $(30.8-32.6)$ & 35.6 & $(34.5-36.7)$ & 40.5 & $(39.4-41.6)$ & 44.3 & $(43.4-45.2)$ & 43.2 & $(41.9-44.53)$ \\
\hline \multicolumn{15}{|l|}{ Sex } \\
\hline Men & 25.0 & $(24.1-25.9)$ & 33.9 & $(32.9-34.9)$ & 35.7 & $(34.5-36.9)$ & 39.0 & $(37.6-40.4)$ & 44.2 & $(42.8-45.6)$ & 45.8 & $(44.5-47.1)$ & 44.5 & $(42.7-46.3)$ \\
\hline Women & 18.4 & $(17.5-19.3)$ & 25.9 & $(25.0-26.8)$ & 26.6 & $(25.4-27.8)$ & 31.3 & $(29.8-32.8)$ & 36.1 & $(34.7-37.5)$ & 42.4 & $(41.2-43.6)$ & 41.7 & $(39.9-43.5)$ \\
\hline \multicolumn{15}{|c|}{ Race/ethnicity† } \\
\hline White & 23.2 & $(22.5-23.9)$ & 31.7 & $(30.9-32.5)$ & 33.3 & $(32.4-34.2)$ & 37.0 & $(35.8-38.2)$ & 42.3 & $(41.1-43.5)$ & 45.7 & $(44.7-46.7)$ & 45.1 & $(43.7-46.5)$ \\
\hline Black & 13.9 & $(12.0-15.8)$ & 18.7 & $(17.1-20.3)$ & 16.8 & $(14.7-18.9)$ & 23.7 & $(20.9-26.5)$ & 28.4 & $(25.9-30.9)$ & 35.7 & $(33.1-38.3)$ & 30.6 & $(26.9-34.3)$ \\
\hline \multicolumn{15}{|l|}{$\begin{array}{r}\text { Education } \\
\text { (years) } \ddagger\end{array}$} \\
\hline$\leqslant 8$ & NA & & 28.7 & $(27.3-30.1)$ & 30.1 & $(27.7-32.5)$ & 34.2 & $(31.6-36.8)$ & 39.2 & $(35.8-42.6)$ & 38.8 & $(35.2-42.4)$ & 39.3 & $(33.9-44.7)$ \\
\hline $9-11$ & NA & & 26.7 & $(25.5-27.9)$ & 26.1 & $(24.0-28.2)$ & 29.3 & $(26.8-31.8)$ & 31.2 & $(28.9-33.5)$ & 32.5 & $(30.2-34.8)$ & 29.5 & $(26.2-32.8)$ \\
\hline 12 & NA & & 32.2 & $(31.2-33.2)$ & 33.2 & $(31.7-34.7)$ & 36.8 & $(34.9-38.7)$ & 39.5 & $(37.9-41.1)$ & 42.0 & $(40.6-43.4)$ & 40.6 & $(38.6-42.6)$ \\
\hline $13-15$ & NA & & 35.7 & $(33.9-37.5)$ & 37.4 & $(34.9-39.9)$ & 39.4 & $(37.3-41.5)$ & 44.5 & $(42.3-46.7)$ & 48.9 & $(46.9-50.9)$ & 48.0 & $(45.3-50.7)$ \\
\hline$\geqslant 16$ & NA & & 48.3 & $(45.9-50.7)$ & 48.5 & $(45.3-51.7)$ & 52.2 & $(49.5-54.9)$ & 59.6 & $(57.3-61.9)$ & 65.1 & $(63.2-67.0)$ & 67.3 & $(64.6-70.0)$ \\
\hline
\end{tabular}

Source: National Health Interview Survey (NHIS), 1965, 1970, 1974, 1979, 1985, 1990, and 1994.

*The prevalence of cessation is defined as the percentage of ever-smokers who are former smokers.

†Ethnicity not determined by NHIS in 1965, 1970, or 1974 .

$\ddagger$ Aged 25 and older only.

$\mathrm{CI}=$ confidence intervals; $\mathrm{NA}=$ not available 
Table 3 Logistic regression analysis of former vs current smoking-age 65 and older: United States, 1993-94

\begin{tabular}{|c|c|c|c|c|}
\hline Variable & $\begin{array}{l}\text { Prevalence of } \\
\text { cessation } \\
(\%)\end{array}$ & $(95 \% C I)$ & Odds ratio ${ }^{\star}$ & $(95 \% C I)$ \\
\hline \multicolumn{5}{|l|}{ Age (years) } \\
\hline $65-69$ & 72.2 & $69.7-74.6$ & 1.00 & \\
\hline $70-74$ & 77.5 & $74.9-80.0$ & 1.37 & $1.13-1.66$ \\
\hline $75-79$ & 78.7 & $75.4-81.9$ & 1.51 & $1.22-1.87$ \\
\hline$\geqslant 80$ & 83.6 & $80.2-87.1$ & 2.19 & $1.64-2.93$ \\
\hline \multicolumn{5}{|l|}{ Education } \\
\hline$\leqslant 8$ years & 74.0 & $70.7-77.3$ & 0.92 & $0.71-1.20$ \\
\hline $9-11$ years & 72.8 & $69.0-76.6$ & 1.00 & \\
\hline High school diploma & 76.8 & $74.4-79.3$ & 1.23 & $0.97-1.56$ \\
\hline Some college & 79.8 & $76.2-83.4$ & 1.44 & $1.06-1.94$ \\
\hline College graduate & 81.8 & $78.2-85.4$ & 1.55 & $1.12-2.14$ \\
\hline \multicolumn{5}{|l|}{ Race (male) } \\
\hline White & 82.5 & $80.5-84.6$ & 2.60 & $1.70-3.98$ \\
\hline Black & 61.6 & $52.3-70.9$ & 1.00 & \\
\hline Hispanic & 84.7 & $72.9-96.6$ & 3.67 & $1.19-11.37$ \\
\hline \multicolumn{5}{|l|}{ Race (female) } \\
\hline White & 71.1 & $68.7-73.5$ & 1.29 & $0.89-1.87$ \\
\hline Black & 63.0 & $54.9-71.1$ & 1.00 & \\
\hline Hispanic & 74.5 & $60.6-88.4$ & 1.90 & $0.82-4.41$ \\
\hline
\end{tabular}

Source: National Health Interview Survey (NHIS), 1993 and 1994.

Hosmer-Lemeshow goodness-of-fit test: $\mathrm{C}-\mathrm{Hat}=12.906 ; \mathrm{df}=8 ; \mathrm{P}=0.12$.

*Adjusted for age, sex, race, and education.

$\mathrm{CI}=$ confidence intervals. and women was shown to decrease withoincreasing age among those aged 65 and older. ${ }^{31}$ It has also been reported that the eldesto of the elderly have the highest quit rates. ${ }^{36}{ }^{43} \frac{7}{7}$ Cumulative quitting over time will result in $a^{\circ}$ lower prevalence of smoking and a higher $\overrightarrow{\overrightarrow{\vec{s}}}$ prevalence of cessation among older adults. 0 However, as continuing smokers are also less드 likely to survive to old age, this differential $\frac{\bar{\omega}}{5}$ mortality may result in a greater apparent ${ }_{\Omega}^{\Phi}$ decrease in smoking prevalence and a greater@ apparent increase in the prevalence of $\rightarrow$ cessation among older age groups. ${ }^{6}$ Other fac-. tors reported in the literature to be associated $\vec{\omega}$ with quitting among those aged 65 and older $\stackrel{\odot}{\circ}$ are smoking fewer cigarettes per day, shorter? duration of smoking, and diagnosis of myocar- $\stackrel{\omega}{\omega}$ dial infarction, stroke, or cancer. ${ }^{36}$

In 1992, only $60 \%$ of elderly American vे smokers received advice to quit from a을 physician. ${ }^{44}$ Because the success rate for older $\vec{\rho}$ smokers who try to quit is generally higher $\mathbb{D}$ than that for younger smokers, ${ }^{374-48}$ and $\underset{\mathbb{D}}{0}$ because of the major health effects and adverse 3 impact on quality of life among elderly people who continue to smoke, it is time to focus more $\vec{c}$ attention in the United States on helping elderly smokers quit. Older smokers began smoking decades ago when the health consequences of smoking were not as well known. Although many older smokers have been addicted to nicotine for decades, the $\frac{0}{D}$ literature has documented successful cessation $\stackrel{2}{\rightarrow}$ interventions for older smokers, including phy- $\overrightarrow{\bar{O}}$ sician advice to quit, as well as follow up, and motivational strategies addressing health beliefs. ${ }^{49-51}$ The Agency for Health Care Policy and Research in the US Department of Health $\frac{0}{0}$ and Human Services recently released clinical practice guidelines that call for healthcare pro- $\delta$ viders to enquire if their patients smoke, repeatedly encourage them to quit, and provide $\overrightarrow{\overrightarrow{0}}$ interventions that have proven to be effective. ${ }^{52} \frac{\mathrm{O}}{\sigma}$ Because those aged 65 years and older have 3 more annual physician contacts than any other age group (9.7 for men, 11.0 for women), ${ }^{53}$ physicians have multiple opportunities to 을 encourage their older patients to improve their health status and quality of life by quitting 을. smoking. relapse rate among black smokers. ${ }^{37}$ It has been suggested that use of cigarettes with higher nicotine and tar levels, a higher level of nicotine dependency among smokers, comparatively limited access to preventive health services, and the lack of culturally sensitive cessation services for black smokers are potential explanations for this difference. ${ }^{37-40}$

Our findings that the prevalence of cessation increases with increasing educational attainment and that education is an important predictor of smoking cessation among older adults (even after adjustment for other demographic factors) are consistent with other data showing that education is the strongest predictor of both smoking prevalence and quitting. ${ }^{12} 374142$

Other studies have also reported that age is a significant predictor of current smoking among the elderly: current smoking among both men
1 US Bureau of the Census. Statistical abstract of the United States, 1996. (116th ed). Washington, DC: Bureau of the Census, Department of Commerce, Economics and 0 Statistics Administration, 1996.

2 LaCroix AZ, Omenn GS. Older adults and smoking. Clin $\mathbb{D}$ Geriatr Med 1992;8:69-87

3 Agner E. Smoking and health in old age: a ten-year $\square$ follow-up study. Acta Med Scand 1985;218:311-16

4 Kaplan GA, Seeman TE, Cohen RD, Knudsen LP, County Study: behavioral and demographic risk factors. Am $\mathcal{F}$ Public Health 1987;77:307-12.

5 LaCroix AZ. Smoking and mortality among older men and $\underset{\gamma}{ }$ women in three communities. $N$ Engl $f$ Med 1991; women in three communities. N Engl f Med 1991; ᄋ

6 US Department of Health and Human Services. The health benefits of smoking cessation. A report of the Surgeon General, 1990. Rockville, Maryland: Public Health Service, Centers for Disease Control, Office on Smoking and Health, 1990 . (DHHS Publication No (CDC) 90-8416.)

7 US Department of Health and Human Services. The health consequences of smoking: chronic obstructive lung disease. $A$ report of the Surgeon General, 1984. Rockville, Maryland: Public Health Service, Office on Smoking and Health, 1984. (DHHS Publication No (PHS) 84-50205.) Guralnik J. Mortality among the elderly in the Alameda $\bigcirc$ 
8 Jajich CL, Ostfeld AM, Freeman DH. Smoking and coronary heart disease mortality in the elderly. $\mathscr{F} A M A$ 1984;252:2831-4.

9 Khaw KT, Barrett-Connor E, Suarez L, Criqui $\mathrm{MH}$ Predictors of stroke-associated mortality in the elderly. Stroke 1984;15:244-8.

10 Shinton R, Beevers G. Meta-analysis of relation between cigarette smoking and stroke. BMF 1989;298:789-94

11 Harris T, Cook EF, Kannel WB, Goldman L. Proportiona hazards analysis of risk factors for coronary heart disease in individuals aged 65 or older: The Framingham Heart Study. $\mathcal{F}$ Am Geriatr Soc 1988;36:1023-8.

12 US Department of Health and Human Services. Reducing the health consequences of smoking: 25 years of progress. $A$ report of the Surgeon General, 1989. Rockville, Maryland: Public Health Service, Centers for Disease Control, Office on Smoking and Health, 1989. (DHHS Publication No on Smoking and

13 US Centers for Disease Control. Cigarette smoking attributable mortality and years of potential life lostUnited States, 1990. MMWR 1993;42:645-9.

14 US Centers for Disease Control and Prevention. SAMMEC 3.0 computer software and documentation, 1996.

15 Guralnik JM, Kaplan GA. Predictors of healthy aging. $A m \mathcal{f}$ Public Health 1989;79:703-8.

16 Pinsky JL, Leaverston PE, Stokes J. Predictors of good function: the Framingham Study. $f$ Chron Dis 1987; 40(suppl):159S-167S

17 Hicks R, Dysken MW, Davis JM, Lesser J, Ripeckyj A Lazarus $L$. The pharmacokinetics of psychotropic medication in the elderly: A review. F Clin Psychiatry 1981 42:374-85.

18 Hermanson B, Omenn GS, Kronmal RA, Gersh BJ. Beneficial six-year outcome of smoking cessation in older men and women with coronary artery disease. $N$ Engl $7 \mathrm{Med}$ 1988;319:1365-9.

19 Rimer BK, Orleans CT. Older smokers. In: Orleans CT, Slade J, eds. Nicotine addiction: principles and management. New York: Oxford University Press, 1993:385-95.

20 Hirdes JP, Maxwell CJ. Smoking cessation and quality of life outcomes among older adults in the Cambell's Survey on outcomes among older adults in the Cambell's S
Well-Being. Can f Public Health 1994;85:99-102.

21 Marcus SE, Pierce JP, Giovino GA, Kleinman JC, Novotn TE. Regional trends in cigarette smoking behavior in the United States. Tobacco Control 1992;1:107-13.

22 Gilpin EA, Pierce JP, Cavin SW, et al. Estimates of population smoking prevalence: self- vs proxy reports of smokin status. Am f Public Health 1994;84:1576-9.

23 Machlin SR, Kleinman JC, Madans JH. Validity of mortality analysis based on retrospective smoking information. Stat Med 1989;8:997-1009.

24 US Department of Health and Human Services. Preventing tobacco use among young people. A report of the Surgeon General, 1994. Atlanta, Georgia: Public Health Service, Centers for Disease Control and Prevention, Office on Smoking and Health, 1994. (US Government Printing Office No S/N 017-001-00491-0.)

25 US Centers for Disease Control and Prevention. Cigarette smoking among adults-United States, 1993. MMWR 1994;43:925-30

26 US Centers for Disease Control and Prevention. Cigarette smoking among adults-United States, 1994. MMWR 1996;45:588-90.

27 National Center for Health Statistics. Current estimates from the health interview survey. United States-1977. Series 10 the health interview survey. United States-1977. Series 10, Number 126. Hyattsville, Maryland: US Department of Health, Education, and Welfare, Public Health Service,
National Center for Health Statistics, 1978. (DHEW PubNational Center for Health Station No (PHS) 78-1554.)
lication

28 Shah BV, Barnwell BG, Hunt PN, LaVange LM. SUDAAN user's manual, release 5.50 with 6.10 addenda. Research Triangle Institute, Research Triangle Park, North Carolina, 1991.

29 Hosmer DW, Lemeshow S. Applied logistic regression. New York: John Wiley \& Sons, 1989.

30 Smoking prevalence and lung cancer death rates. In: Strategies to control tobacco use in the United States: a blueprint for public health action in the 1990s. Bethesda. Maryland: US Department of Health and Human Services, Public Health Service, National Institutes of Health, National Cancer Institute, 1991. (NIH Publication No 92-3316.)
31 Colsher PL, Wallace RB, Pomrehn PR, et al. Demographic and health characteristics of elderly smokers: results from Established Populations for Epidemiologic Studies of the Elderly. Am F Prev Med 1990;6:61-70.

32 Novotny TE, Fiore MC, Hatziandreu EJ, Giovino GA, Mill SL, Pierce JP. Trends in smoking by age and sex, United States, 1974-1987: the implications for disease impact. Prev Med 1990;19:552-61.

33 Califano JA. The impact of substance abuse. Tobacco Contro 1995;4(suppl 2):S19-24.

34 Husten CG, Chrismon JH, Reddy MN. Trends and effects of cigarette smoking among girls and women in the United States, 1965-1993. F Am Med Wom Assoc 1996;51:11-18.

35 Shopland DR. Tobacco use and its contribution to early cancer mortality with a special emphasis on cigarette smoking. Environ Health Perspect 1995;103(suppl 8):131 41

36 Salive ME, Cornoni-Huntley J, LaCroix AZ, Ostfeld AM Wallace RB, Hennekens CH. Public health beliefs. $A m \mathcal{F}$ Public Health 1992;82:1268-71.

37 US Centers for Disease Control. Smoking cessation during previous year among adults-United States, 1990 and previous year among adults-
1991. $M M W R$ 1993;42:504-7.

38 US Department of Health and Human Services. The health consequences of smoking: nicotine addiction. A report of the Surgeon General, 1988. Rockville, Maryland: Public Health Service, Centers for Disease Control, Office on Smoking and Health, 1988. (DHHS Publication No (CDC) 88-8406.)

39 Royce JM, Hymowitz N, Corbett K, Hartwell TD, Orland MA, for the COMMIT Research Group. Smoking cessation factors among African Americans and whites. Am $₹$ Public Health 1993;83:220-6.

40 Hymowitz N, Sexton M, Ockene J, Grandits G, for the MRFIT Research Group. Baseline factors associated with MRFIT Research Group. Baseline factors associated with
smoking cessation and relapse. Prev Med 1991;20:590601 .

41 Pierce JP, Fiore MC, Novotny TE, Hatziandreu EJ, Davis RM. Trends in cigarette smoking in the United States: Educational differences are increasing. $\mathscr{F} A M A 1989$ 261:56-60.

42 Zhu BP, Giovino GA, Mowery PD, Eriksen MP. The relationship between cigarette smoking and education revisited: implications for categorizing persons' educational status. Am $¥$ Public Health 1996;86:1582-9.

43 Kabat GC, Wynder EL. Determinants of quitting. $A m \mathcal{F}$ Public Health 1987;77:1301-5.

44 Tomar SL, Husten CG, Manley MW. Do dentists and physicians advise tobacco users to quit? $\mathcal{f} \mathrm{Am}$ Dent Assoc 1996;127:259-65.

45 McWhorter WP, Boyd GM, Mattson ME. Predictors of quitting smoking: the NHANES I followup experience. $f$ Clin Epidemiol 1990;43:1399-405.

46 Kirscht JP, Brock BM, Hawthorne VM. Cigarette smoking and changes in smoking among a cohort of Michigan and changes in smoking among a cohort of Mich

47 Hatziandreu EJ, Pierce JP, Lefkopoulou M, et al. Quitting smoking in the United States in 1986. F Natl Cancer Ins 1990;82:1402-6.

48 Pierce J, Giovino G, Hatziandreu, E, Shopland D. National age and sex differences in quitting smoking. $\mathcal{F}$ Psychoactive Drugs 1989;21:293-8.

49 Morgan GD, Noll EL, Orleans CT, et al. Reaching midlife and older smokers: tailored interventions for routine medical care. Prev Med 1996;25:346-54.

50 Orleans CT, Jepson C, Resch N, Rimer BK. Quitting motives and barriers among older smokers. Cancer 1994;74:2055-61.

51 Boyd NR. Smoking cessation: a four-step plan to help older smokers quit. Geriatrics 1996;51:52-7.

52 Fiore MC, Bailey WC, Cohen SJ, et al. Smoking cessation. Clinical Practice Guideline No 18. Rockville, Maryland: US Department of Health and Human Services, Public Health Service, Agency for Health Care Policy and Research, April 1996. (AHCPR Publication No 96-0692.)

53 US Department of Health and Human Services. Current estimates from the Nation Health Interview Survey. In Vital and health statistics, Series 10, No 184. Hyattsville, Maryland: Public Health Service, Centers for Disease Control, National Center for Health Statistics, 1992. 